\title{
Patentes de formas polimórficas na área de fármacos no Brasil e o impacto na saúde pública
}

\author{
DOI: 10.3395/reciis.v4i2.331pt
}

\section{Jaqueline Mendes Soares}

Instituto de Medicina Social, Universidade Estadual do Rio de Janeiro, Instituto Nacional da Propriedade Industrial,

Rio de Janeiro, Brasil

jsoares@inpi.gov.br

\section{Marilena Cordeiro Dias Villela Correa}

Instituto de Medicina Social, Universidade Estadual do Rio de Janeiro, Rio de Janeiro, Brasil

\section{Liane Elizabeth Caldeira Lage}

Instituto Nacional da Propriedade Industrial, Rio de Janeiro, Brasil

\begin{abstract}
Resumo
O artigo pretende demonstrar como o Instituto Nacional da Propriedade Industrial (INPI) está examinado os pedidos de patente relativos às formas polimórficas na área farmacêutica. Para tanto foi feito um levantamento do número de pedidos de patente nesta área já analisados pelo INPI no período de janeiro de 2008 a março de 2009. Os resultados revelam que a maioria dos pedidos de patente não preenche alguns dos requisitos de patenteabilidade, assim como da condição de suficiência descritiva, conforme as disposições legais da Lei 9.279/96 (LPI) e a proposta de diretrizes de exame elaborada pelo Instituto.
\end{abstract}

Palavras-chave

medicamentos; polimorfos; forma cristalina
Polimorfos: definição, propriedades e proteção patentária

O termo polimorfismo pode ser definido como a existência de alterações no arranjo cristalino de uma substância sem, porém, observar-se modificação na estrutura das moléculas (conformação molecular e espacial). As propriedades químicas das diferentes formas cristalinas de uma substância são idênticas, mas o mesmo não ocorre com suas propriedades físicas e físico-químicas como, por exemplo, ponto de fusão, condutividade, volume, densidade, viscosidade, cor, índice de refração, solubilidade, higroscopicidade, estabilidade e perfil de dissolução (GIRO et al., 2002).

A presença de diferentes estruturas cristalinas de um princípio ativo pode comprometer a execução das diversas operações na produção de um medicamento como filtração, lavagem, secagem, moagem, liofilização, encapsulamento e compressão, além de afetar suas propriedades de solubilidade e biodisponibilidade (BOTTOM, 1999; BRITTAIN, 2006). Por exemplo, segundo Froehlic, amostras de matérias-primas e medicamentos de mebendazol disponíveis no mercado apresentam diferentes polimorfos em sua composição, o que pode afetar sua dissolução e, consequentemente, sua biodisponibilidade (FROEHLIC et al., 2005).

A patente é considerada um grande incentivo ao desenvolvimento tecnológico, tanto por ser um documento oficial que concede proteção legal à invenção quanto por ser um documento considerado como a mais rica fonte de informação tecnológica no mundo, agregando, em seu conteúdo, dados inéditos que não estão disponíveis em nenhum tipo de publicação técnico-científica. Para proteger uma invenção por meio de uma patente, é necessário que sejam obedecidos os requisitos básicos de patenteabilidade previstos nas legislações de propriedade industrial: novidade, atividade inventiva e aplicação industrial (LONGA, 2007).

Geralmente, as patentes já concedidas nos escritórios internacionais relativas às formas polimórficas na área farmacêutica reivindicam o produto e processos de obtenção de formas cristalinas de fármacos já conhecidos em uma "Fórmula Markush". Tais patentes tornaram-se polêmicas devido ao fato de os titulares utilizarem as formas cristalinas como uma estratégia para a extensão da proteção da molécula base. Ressalta-se que uma "Fórmula Markush" é 
uma expressão genérica para mútiplas entidades químicas funcionalmente equivalentes, permitidas em uma ou mais partes de um composto químico (JANNUZZl et al., 2008).

Em verdade, tal extensão é possível em virtude do escopo da proteção das patentes que vêm sendo concedidas nos escritórios internacionais que, por serem amplas e não definirem corretamente a matéria a ser protegida, permitem a extensão da matéria já revelada no estado da técnica. Em consequência, o acesso ao medicamento é afetado, uma vez que a fabricação de genéricos de produtos que já estariam em domínio público será impedida (PRÓ-GENÉRICOS, 2009).

Inúmeros litígios sobre infração de patentes envolvendo formas cristalinas têm sido relatados na literatura. Como exemplos mais representativos têm-se a discussão acerca da patenteabilidade das formas cristalinas I, II e IV da atorvastatina da Warner Lambert e do cloridrato da paroxetina da Smithkline Beecham (LIMA, 2008).

Para traçar o posicionamento dos diferentes escritórios de patente no âmbito mundial com relação ao patenteamento de formas polimórficas, foi realizada uma consulta à legislação e diretrizes de exame dos seguintes países: Estados Unidos, China, Japão, Argentina, Índia, Comunidade Andina e Escritório Europeu de Patentes. Para a maioria dos países verificou-se que não há um posicionamento claro com relação às formas polimórficas tampouco qualquer impedimento legal quanto ao patenteamento das mesmas. Com relação ao escritório indiano, o polimorfo é passível de proteção patentária desde que preencha os requisitos de patenteabilidade e apresente eficácia significativamente aumentada em relação à forma anteriormente revelada no estado da técnica (INPI, 2009).

No Brasil, a proteção para produtos e processos farmacêuticos ocorreu até 1945. A partir desta data, com o intuito de fortalecer a indústria nacional, foi proibido no país o patenteamento de produtos e processos farmacêuticos. A Lei $n^{\circ} 5.772$ de 31/12/1971, que instituiu o Código da Propriedade Industrial, manteve como matéria não patenteável as substâncias, matérias, misturas ou produtos alimentícios, químico-farmacêuticos e medicamentos de qualquer espécie, bem como os respectivos processos de obtenção ou modificação (BRASIL, 1971).

Após grande pressão internacional dos países desenvolvidos, em 1994, após as negociações na rodada do Uruguai do Gatt (Acordo Geral sobre Território e Comércio)/ OMC, o Brasil assinou o acordo Trips - Acordo sobre os Aspectos dos Direitos de Propriedade Intelectual Relacionados ao Comércio. Neste acordo, todas as invenções, em qualquer área tecnológica, devem ser passíveis de proteção patentária, conforme redação dada em seu artigo 27 (BERMUDEZ,
2000). Dessa forma, compreende-se que a inclusão do Brasil no Trips demonstrou a intenção do País em harmonizar sua legislação com as de outras nações. Portanto, com a nova Lei de Propriedade Industrial (Lei 9.279 de 14/5/1996 - LPI), que entrou em vigor em 14/5/97, passaram a ser concedidas patentes de medicamentos no país (TACHINARD, 1993). Convém destacar que a referida Lei não faz menção a patenteabilidade ou não de formas polimórficas dos medicamentos e, devido à necessidade de elaboração de novas diretrizes de exame que abrangem aspectos específicos das patentes farmacêuticas, como é o caso das formas polimórficas, o Instituto Nacional da Propriedade Industrial (INPI) iniciou um ciclo de discussões técnicas para debater com a sociedade este tema (INPI, 2009).

Nesse contexto, para avaliar o cenário atual acerca da patenteabilidade das formas polimórficas no Brasil, fez-se um levantamento do número de pedidos analisados pelo INPI no período de janeiro de 2008 a março de 2009, bem como uma avaliação crítica do resultado da aplicação da proposta de diretrizes de exame do referido órgão.

Convém destacar que o INPI é uma autarquia federal vinculada ao Ministério do Desenvolvimento, Indústria e Comércio responsável por registros de marcas, concessão de patentes, averbação de contratos de transferência de tecnologia e de franquia empresarial, e por registros de programas de computador, desenho industrial e indicações geográficas, de acordo com a LPI e a Lei de Software (Lei n ${ }^{\circ}$ 9.609/98).

Ciclo de discussões técnicas sobre a patenteabilidade de formas polimórficas organizado pelo INPI

Para o INPI, as diretrizes de exame têm por objetivo orientar o examinador na análise dos pedidos de patente, de modo que haja harmonização na análise dos pedidos de patente por diferentes examinadores. As diretrizes de exame em vigor nas áreas biotecnológicas e farmacêuticas foram publicadas em 31/12/2002 na Revista da Propriedade Industrial (RPI) $\mathrm{n}^{\circ}$ 1669. Contudo, com o intuito de harmonizar as referidas diretrizes com aspectos mais específicos das patentes farmacêuticas, como é o caso das formas polimórficas, em meados de junho de 2007, o INPI organizou um ciclo de discussões técnicas em patentes, totalizando três encontros, visando a discutir as condições de patenteabilidade das referidas formas para subsidiar as novas diretrizes de exame na área de fármacos.

O ciclo de discussão contou com a participação de técnicos de outros órgãos e autoridades, tais como a 
Agência de Vigilância Sanitária (Anvisa) e Fundação Oswaldo Cruz (Fiocruz), representantes da Associação Brasileira das Indústrias de Química Fina (Abifina), Associação da Indústria Farmacêutica de Pesquisa (Interfarma) e Finaciadora de Estudos e Projetos (Finep), além de representantes de agências de propriedade industrial (INPI, 2009).

O primeiro encontro ocorreu em 11 de junho de 2007 na sede do INPI. Teve como temas principais o fato de o polimorfismo ser uma propriedade intrínseca da substância, a possibilidade de patentear apenas o processo de obtenção do polimorfo e não o produto em si, e a questão da falta de suficiência descritiva dos processos de obtenção de polimorfos, observadas na grande maioria das patentes já concedidas nos escritórios internacionais. Ressalta-se que a suficiência descritiva é uma condição de patenteabilidade na qual a invenção deve estar descrita de forma a possibilitar a sua reprodução por um técnico no assunto (INPI, 2009).

O segundo encontro ocorreu em 26 de junho de 2007. Inicialmente foram debatidos os aspectos relevantes para aferição da novidade da forma polimórfica, assim como a possibilidade de conceder uma forma polimórfica pelo processo de obtenção. Outra questão bastante discutida foi a necessidade da definição de parâmetros importantes e essenciais à caracterização da forma polimórfica e do processo de obtenção da mesma (INPI, 2009).

No último encontro, ocorrido em 10 de julho de 2007, foram discutidos os vários parâmetros pertinentes à caracterização do processo de obtenção da forma polimórfica, os quais devem estar contemplados no pedido de patente no ato do depósito. Tais parâmetros são essenciais na determinação da fase cristalina do sólido pleiteada para possibilitar a sua reprodução por um técnico no assunto. Dentre os parâmetros imprescindíveis à obtenção da nova forma polimórfica foram mencionados: variação de concentração, mistura de reagentes, adição de sementes, taxa de resfriamento, torque e pressão, entre outros. Por fim, quanto ao requisito da atividade inventiva de uma forma polimórfica, várias opiniões foram emitidas; contudo, não se chegou a uma conclusão definitiva acerca da obviedade ou não para um técnico no assunto (INPI, 2009).

Salienta-se que, após o término do ciclo de discussões técnicas e tendo em vista a impossibilidade de participação ampla de especialistas de todas as áreas, visando à maior transparência possível, o INPI estabeleceu um canal aberto de comunicação por meio de envio de mensagem eletrônica.

Em paralelo ao ciclo de discussões, o corpo especialista em propriedade industrial do INPI, formado por examinadores com mestrado e doutorado nas áreas de engenharia química, química, biologia e farmácia se reuniu na sede do instituto para discutir tecnicamente a patenteabilidade das formas polimórficas na área farmacêutica. Após várias reuniões e consultas técnicas aos membros da sociedade brasileira de cristalografia, bem como a professores das universidades públicas federais, elaborou-se um documento preliminar acerca da patenteabilidade de formas polimórficas na área de fármacos, o qual ficou disponível no endereço eletrônico do INPI para o recebimento de contribuições técnicas acerca deste tema. Após a análise das referidas contribuições técnicas, o INPI tornou pública sua proposta de diretrizes para o exame de pedidos de patente na área de fármacos relativa a formas polimórficas através do endereço eletrônico deste Instituto.

Os principais itens das referidas diretrizes de exame encontram-se descritos resumidamente abaixo:

a) Forma polimórfica

Análise quanto ao requisito de novidade segundo o Art. 11 da LPI

A comparação entre os difratogramas de difração de raios-x de cristal único entre a forma polimórfica reivindicada e aquela já revelada no estado da técnica é suficiente para aferir a novidade do produto reivindicado. Entretanto, não havendo tais dados faz-se necessária a comparação entre os mesmos através da técnica de difração de raios-x pelo método de pó com indexação, além de outros métodos de análise, tais como Espectroscopia de Ressonância Magnética Nuclear de Carbono no Estado Sólido, Espectrometria na Região do Infravermelho, Espectroscopia Raman, Microscopia Eletrônica, Análise Térmica (Calorimetria Diferencial Exploratória, Termogravimetria e Análise Térmica Diferencial). A informação quanto ao grau de pureza da amostra também é importante na aferição da novidade da forma polimórfica pleiteada, visto que impurezas na amostra podem causar interferências na qualidade dos resultados da análise de caracterização da estrutura cristalina. Cabe ressaltar que, para efeito da aferição da novidade da forma cristalina reivindicada, apenas os dados de caracterização da forma cristalina revelada no estado da técnica poderão ser apresentados após a data de depósito da forma pleiteada no pedido de patente.

Análise quanto ao requisito de atividade inventiva segundo o Art. 13 da LPI

A forma polimórfica deverá solucionar um problema do estado da técnica suficientemente diferenciador, por exemplo, aumento na estabilidade, solubilidade e processabilidade, que não decorra de maneira óbvia e evidente do estado da técnica. 
b) Processo de obtenção da forma polimórfica

Análise quanto ao requisito de novidade segundo o Art. 11 da LPI

O processo para obter a forma polimórfica será novo quando o mesmo não estiver descrito no estado da técnica.

Análise quanto ao requisito de atividade inventiva segundo o Art. 13 da LPI

O processo de obtenção da forma polimórfica não deverá decorrer de maneira óbvia ou evidente do estado da técnica. Ou seja, processos usuais de cristalização, em princípio, não seriam patenteáveis visto que é óbvia para um técnico no assunto a utilização dos mesmos para produzir formas polimórficas na área químico-farmacêutica.

Análise quanto à condição de suficiência descritiva segundo o Art. 24 da LPI

Uma vez que uma simples modificação em um processo de cristalização pode acarretar alterações na forma cristalina do produto obtido, é imprescindível que todos os parâmetros envolvidos em um processo de cristalização estejam descritos no pedido de patente, no ato de depósito, de forma a possibilitar a sua reprodução por um técnico no assunto. Alguns exemplos de parâmetros são: solvente, temperatura, concentração, taxa de resfriamento, adição de sementes de cristais, entre outras.

Quanto aos processos em que é feita semeadura de um determinado cristal, a descrição do processo de obtenção da semente é necessária para que o técnico no assunto consiga reproduzi-lo.

c) Composição farmacêutica contendo a forma polimórfica Análise quanto ao requisito de novidade segundo o Art. 11 da LPI

Uma vez constatada que a forma polimórfica reivindicada é nova, a composição contendo a mesma também será considerada nova.

Análise quanto ao requisito de atividade inventiva segundo o Art. 13 da LPI

A avaliação da atividade inventiva deve ser efetuada de forma independente, ou seja, para que a composição contendo a nova forma polimórfica apresente atividade inventiva, deve-se avaliar se o efeito é diferenciador e se resolve um problema técnico de forma comprovada, baseado em parâmetros específicos comparativos da mesma em relação ao estado da técnica. Tendo em vista que qualquer efeito de uma composição pode ser proveniente das ações independentes dos seus ingredientes ou, ainda, das interações de seus ingredientes, para que o examinador possa avaliar os efeitos provenientes da nova forma polimórfica em uma composição devem ser apresentados dados comparativos de composições quantitativamente iguais das formas contidas no estado da técnica.

\section{A proteção de formas polimórficas e a saúde pública}

O ciclo de discussões promovido pelo INPI teve como conseqüência direta o aprofundamento das discussões no país sobre o impacto das patentes farmacêuticas na saúde pública.

Assim, em 28 de novembro de 2007 foi realizada uma primeira audiência pública na Comissão de Direitos Humanos e Minorias da Câmara dos Deputados, na qual foi questionado o possível prejuízo causado pelas patentes no acesso aos medicamentos. Foram levantadas questões como licenciamento compulsório, inconstitucionalidade das patentes pipeline e o compromisso com o fortalecimento da política nacional de acesso a medicamentos (DE OLHO NAS PATENTES, 2009).

Já a audiência pública realizada em 25 de junho de 2008, solicitada pelo deputado Dr. Rosinha (PT-PR), na Comissão de Relações Internacionais da Câmara dos Deputados, teve por objetivo discutir o patenteamento de formas polimórficas no Brasil. A mesa da audiência contou com a participação de representantes da Anvisa, INPI e do Grupo Interministerial de Propriedade Intelectual (Gipi). Segundo o deputado Dr. Rosinha, as empresas multinacionais serão as únicas a se beneficiarem do patenteamento das formas polimórficas e se esta medida for adotada no Brasil, haverá o comprometimento do direito de acesso universal aos medicamentos, visto que medicamentos patenteados são mais caros. Na visão da Anvisa, a patenteabilidade de formas polimórficas pode levar à formação de monopólios o que inibe a concorrência, além de limitar o espaço do inventor nacional. O representante do Gipi, que tem por objetivo a harmonização das posições dos órgãos do poder executivo sobre propriedade intelectual, não adotou nenhuma posição em relação ao patenteamento das novas formas polimórficas. Para o presidente do INPI, o patenteamento de novas formas polimórficas favoreceria o ingresso do país na rede globalizada de inovação tecnológica (CÂMARA DOS DEPUTADOS, 2009).

No dia 30 de outubro de 2008 foi realizada uma audiência pública na Câmara dos Deputados, a qual incluiu representantes do Ministério do Desenvolvimento, Indústria e Comércio (MDIC), Ministério das Relações Exteriores, Ministério da Saúde e o presidente do INPI para discutir o patenteamento na área de fármacos, mais precisamente de 
novas formas polimórficas e segundo uso médico, ou seja, o novo uso de um medicamento já conhecido. Nesta audiência pública foi amplamente discutido que não compete ao INPI estabelecer regras e, portanto, suas diretrizes de exame deveriam ser encaminhadas para aprovação no âmbito do Gipi (ASSOCIAÇÃO BRASILEIRA INTERDISCIPLINAR DE AIDS, 2009).

Ainda nesse mesmo ano, em 1 de dezembro de 2008 o GIPI reuniu-se em sessão plenária, além de representantes do INPI e da Anvisa, na qual foi argumentado pelo representante do Ministério da Saúde (MS) que a concessão de patentes de invenções incrementais são contrárias às políticas públicas na área de saúde, assim como ao desenvolvimento do complexo industrial da saúde no país. Entretanto, o representante do INPI alertou que a proposta de diretrizes de exame relativas a formas polimórficas elaboradas pelo órgão é bastante exigente e restritiva, e que sua aplicação tem restringido a concessão de patentes nesta área do conhecimento àquelas que efetivamente atendem aos requisitos legais (novidade, atividade inventiva e aplicação industrial) e à condição de suficiência descritiva. O presidente do INPI também alertou que o ideal seria propor alterações legislativas que confiram segurança jurídica à ação pretendida pelo Gipi de não concessão de patentes às formas polimórficas. Por fim, o GIPI decidiu em sua última reunião limitar a concessão de patentes de medicamentos no País. Tal posição é uma resposta à polêmica em torno dos pedidos depositados no INPI que pleiteiam proteção para segundo uso médico (INSTITUTO BRASILEIRO DE DEFESA DO CONSUMIDOR, 2009).

Em 23 de setembro de 2008, foi apresentado um projeto (PL 3.995 de 2008), de autoria do deputado Paulo Teixeira (PT-SP), que propõe três alterações no Art. 10 da LPI, a saber: proibição de concessão de patentes para um novo uso médico de um fármaco, proibição de patentes para novas formas cristalinas de substâncias conhecidas e, por último, a substituição do termo "métodos operatórios" por "modelos operatórios". No entendimento dos autores do referido projeto de lei, o fenômeno do polimorfismo é uma propriedade intrínseca das substâncias químicas com propriedades farmacêuticas, as quais podem se apresentar sob formas diferentes em seu estado cristalino. Assim, a proposta de inclusão de um novo dispositivo ao Art. 10 da LPI atenderia, de acordo com os autores do projeto de lei, os interesses sociais e o desenvolvimento tecnológico e econômico do Brasil (DIÁRIO DA CÂMARA DOS DEPUTADOS, 2009).

Na Lei 9.279/96 o Art. 10 refere-se às matérias que não são consideradas invenções tais como:

I- descobertas, teorias científicas e métodos matemáticos;
II- concepções puramente abstratas;

III- esquemas, planos, princípios ou métodos comerciais, contábeis, financeiros, educativos, publicitários, de sorteio e de fiscalização;

IV- as obras literárias, arquitetônicas, artísticas e científicas ou qualquer criação estética;

V- programas de computador em si;

VI- apresentação de informações;

VII - regras de jogo;

VIII - técnicas e métodos operatórios, bem como métodos terapêuticos ou de diagnóstico, para aplicação no corpo humano ou animal; e

IX - o todo ou parte de seres vivos naturais e materiais biológicos encontrados na natureza, ou ainda que dela isolados, inclusive o genoma ou germoplasma de qualquer ser vivo natural e os processos biológicos naturais.

Em função da proposta do PL 3.995 de 2008 o Art. 10 da LPI teria a seguinte redação quanto às formas polimórficas: "Art. 10 - Não se considera invenção nem modelo de utilidade: XI - produtos de composição química idêntica, mas que apresentam formas cristalinas diferentes, quer estejam sob proteção de patente, quer estejam sob domínio público".

Cabe ressaltar que o PL 3.955 de 2008 foi apensado ao PL 2.511 de 2007, de autoria do deputado Fernando Coruja, que se refere ao impedimento de proteção patentária dos produtos e processos farmacêuticos que formulem nova indicação.

Assim, atualmente a patenteabilidade de formas polimórficas encontra-se em fase de discussão envolvendo vários órgãos governamentais e representantes da sociedade civil, bem como da câmara legislativa.

\section{Pedidos de patente relacionados a formas polimórficas de fármacos analisados pelo INPI de janeiro de 2008 a março de 2009}

Não havendo restrições legais ao patenteamento da matéria em discussão, o INPI vem examinando os pedidos de formas polimórficas na área farmacêutica com base na legislação vigente.

Uma patente, enquanto não decidida, gera expectativa de direito, efetivamente funcionando como bloqueio ao uso da matéria pleiteada. Além disso, quanto mais tempo for postergada uma decisão acerca da patenteabilidade das formas polimórficas, maior tempo de vigência poderá ter a patente, caso concedida, ou seja, mais de 20 anos a contar da data do depósito, visto que, segundo o Art. 40 da LPI, o prazo de vigência de uma patente de invenção não poderá ser 
inferior a 10 anos a contar da data da concessão, ressalvada a hipótese de o INPI estar impedido de proceder ao exame

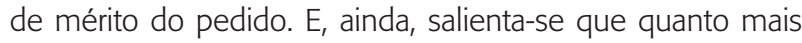
tempo demorar a decisão acerca da matéria pleiteada mais se inviabiliza a entrada de medicamentos genéricos no mercado uma vez que enquanto em trâmite o pedido de patente, existe a expectativa de direito.

A metodologia do presente estudo consistiu na pesquisa de palavras tais como: modificação, forma, polimórfica, cristais e suas variações no título dos pedidos de patente relativos às formas polimórficas na área farmacêutica publicados pelo INPI na Revista da Propriedade Industrial (RPI) durante o período de janeiro de 2008 a março de 2009. Assim, foram recuperadas as RPIs de n’s 1930, 1939, 1941, 1942, 1946, 1967, 1968, 1972, 1975, 1983, 1986 a 1989, 1991 e 1995.

A RPI é a publicação oficial do INPI onde são publicados todos os seus atos, despachos e decisões relativas ao sistema de propriedade industrial no Brasil. É editada semanalmente e pode ser consultada gratuitamente na biblioteca do INPI e nas delegacias, representação regional e postos avançados, bem como no endereço eletrônico do INPI (www.inpi.gov.br).

A RPI apresenta uma tabela de código de despachos e cada código vem acompanhado de explicação precisa da fase processual dos pedidos, patentes e desenhos industriais que tramitam no INPI, bem como das providências a serem adotadas pelos respectivos depositantes ou procuradores por eles designados. Assim, é possível verificar a matéria do pedido de patente e identificar o andamento do pedido ou patente através dos códigos de despacho.

Com os números dos pedidos de patente relativos a formas polimórficas, a etapa seguinte do presente trabalho consistiu na leitura dos pareceres de exame com o objetivo de verificar quais os artigos da LPI, assim como os argumentos técnicos, que foram utilizados pelos examinadores da divisão técnica responsável acerca da patenteabilidade ou não das formas polimórficas. Os pareceres de exame de cada pedido de patente podem ser obtidos através da solicitação de fotocópia dos mesmos ao INPI, que é um serviço disponibilizado a qualquer pessoa física ou jurídica.

No processamento de exame de um pedido de patente, o examinador deve emitir um parecer técnico (Art. 35 da LPI) expondo suas conclusões, que podem ser: pela concessão da patente, pela elaboração de exigências técnicas e ciência de parecer (quando o pedido não atende aos requisitos de patenteabilidade) e pelo indeferimento do pedido.

Se a decisão for pela patenteabilidade do pedido, ou seja, decisão de deferimento (publicado como código de despacho 9.1) significa que não foram encontradas anterioridades impeditivas, que o pedido atende aos requisitos de patenteabilidade e aos Atos Normativos do INPI.

Caso sejam formuladas exigências técnicas (publicado como código de despacho 6.1) para reformulação do pedido, a fim de que o mesmo possa receber a patente requerida, o depositante terá 90 dias para o cumprimento das mesmas. Quando a exigência não é respondida dentro do prazo, o pedido é arquivado definitivamente (Art. 36 da LPI). Respondida a exigência, e ainda que não cumprida, o examinador pode formular novas exigências técnicas no sentido de sanar as irregularidades do pedido de patente (segundo exame) e, novamente o depositante terá 90 dias para o cumprimento das mesmas.

No caso de um pedido de patente possuir evidências de não patenteabilidade é emitido um parecer de ciência (publicado com código de despacho 7.1) e o depositante terá 90 dias para se manifestar e apresentar suas argumentações acerca do mesmo. Caso o examinador considere as argumentações apresentadas pelo depositante como pertinentes, o pedido será deferido. Entretanto, caso as argumentações ainda não sejam suficientes para sanar totalmente as evidências de não patenteabilidade, um novo parecer de exigência ou ciência pode ser emitido. Se o depositante não apresentar resposta ao parecer emitido o pedido é arquivado. $E$, ainda, se as argumentações forem consideradas improcedentes, o pedido será indeferido.

O indeferimento do pedido (publicado com código de despacho 9.2) significa que o mesmo não atende aos requisitos e condições de patenteabilidade expressos na LPI. Cabe ressaltar que o pedido de patente não pode ser indeferido em primeiro exame, ou seja, só pode ser indeferido após parecer de exigência não cumprida ou de ciência.

Em uma segunda instância, o depositante terá oportunidade de se manifestar antes de uma decisão final através da interposição de recurso contra o indeferimento, no prazo de sessenta dias da notificação do indeferimento na RPI. Na fase de recurso o pedido de patente é examinado por um técnico diferente daquele que opinou pelo indeferimento e, após análise por um colegiado, é emitido um novo parecer técnico que pode decidir por manter o indeferimento ou pela reversão do mesmo. Caso o parecer seja por manter o indeferimento, neste momento é encerrada a fase administrativa e a discussão acerca da patenteabilidade do pedido ainda poderá ser questionada na instância judicial. Se o colegiado decidir pela reversão do indeferimento, o exame segue o trâmite normal, sendo encaminhado à Anvisa para anuência prévia de acordo com o Art.229-C da LPI. Caso a anuência seja concedida, o INPI publica o deferimento do pedido. 
No Quadro 1, os resultados da pesquisa realizada estão apresentados, destacando-se o número do pedido de patente, depositante, assunto e a situação no INPI, assim como os números dos pedidos de patentes relativos às formas polimórficas analisados pela Divisão de Química II (Diquimll) do INPI, no período supracitado.

Quadro 1: Pedidos analisados pelo INPI relativos a formas polimórficas no período de janeiro de 2008 a março de 2009.

\begin{tabular}{|c|c|c|c|}
\hline $\begin{array}{l}\mathrm{N}^{\circ} \text { do } \\
\text { Pedido }\end{array}$ & Depositante & Assunto & Situaçăo no INPI \\
\hline PI9603540-4 & Tioga Pharmac. & $\begin{array}{l}\text { Nova forma termodinamicamente estável ao calor de } \mathrm{N} \text {-metil-n-[(1s)-1-fenil-2- } \\
((3 \mathrm{~s})-3 \text {-hidróxi-pirrolidin-1-il)etil]-2,2-difenilacetamida }\end{array}$ & 7.1 (RPI 1975 de 11/11/2008) \\
\hline P19611229-8 & Merck \& Co Inc. & $\begin{array}{l}\text { Forma polimórfica do composto metanossulfonato de } \mathrm{N} \text {-[1(R)-[(1,2-di-hidro-1- } \\
\text { metanossulfonil espiro[3H-indol-3,4-piperidin] 1-il)-carbonil]-2-(fenilmetil- } \\
\text { oxi)etil]-2-amino-2-metilpropanamida. }\end{array}$ & 9.2 (RPI 1941 de 18/03/2008) \\
\hline PI9711151-1 & G.D. Searle \& Co & Forma cristalina de 4-[5-metil-3-fenilisoxazol-4-IL] Benzenossulfonamida & 9.2 (RPI 1942 de 25/03/2008) \\
\hline PI9712072-3 & Meiji Seika Kaisha Ltd. & Substância cristalina de Cefditoren Pivoxil e processo de obtenção. & 9.2 (RPI 1968 de 23/09/2008) \\
\hline P19714059-7 & Astrazeneca $\mathrm{AB}$ & $\begin{array}{l}\text { S-Omeprazol em uma forma neutra, processo de preparação e composição } \\
\text { farmacêutica. }\end{array}$ & 7.1 (RP1989 de 17/02/2009) \\
\hline P19714081-3 & Sanofi-Aventis & $\begin{array}{l}\text { Processo para a cristalização do cloridrato de 1-[2-(2-naftil)etil]-4-(3- } \\
\text { trifluorometilfenil)-1,2,3,6-tetraidropiridina (SR } 57746 \text { A). }\end{array}$ & 9.2 (RPI 1967 de 16/09/2008) \\
\hline PI9804946-1 & Novartis Ag & Modificação de cristal de um agente farmacêutico & 9.2 (RPI 1972 de 21/10/2008) \\
\hline P19804947-0 & Novartis Ag & Modificação de cristal de um agente farmacêutico & 9.2 (RPI 1972 de 21/10/2008) \\
\hline P19816234-9 & Sanofi-Aventis & $\begin{array}{l}\text { Nova forma de cristal de } n \text {-(4-trifluormetilfenil)-5-metilisoxazol-4- } \\
\text { carboxamida. }\end{array}$ & 7.1 (RP1986 de 27/01/2009) \\
\hline P19806784-2 & $\begin{array}{l}\text { Viatris GMBH \& CO. } \\
\qquad \mathrm{KG}\end{array}$ & $\begin{array}{l}\text { Modificaçôes do 2-amino-4-(4-fluorobenzilamino)-1-etoxicarbonil- } \\
\text { aminobenzeno e processo de preparação }\end{array}$ & 9.2 (RPI 1983 06/01/2009) \\
\hline PI9810360-1 & Merck \& CO, INC & $\begin{array}{l}\text { Forma polimórfica do composto 2-(R)-(1-(R)-(3,5-bis(tri- } \\
\text { fluorometil)fenil)etoxi)-3-(S)-(4-fluoro)fenil-4(3-(5-oxo-1H,4H-1,2,4- } \\
\text { triazolo)metilmorfolino e processo de preparaçāo. }\end{array}$ & 9.2 (RPI 1983 de 06/01/2009) \\
\hline P19810483-7 & Astrazeneca AB & Forma B de Omeprazol-sódico e processos de preparação. & 7.1 (RPI 1939 de 04/03/2008) \\
\hline P19810776-3 & $\begin{array}{l}\text { Roche Dignostics } \\
\text { Gmbh }\end{array}$ & $\begin{array}{l}\text { Modificação termodinamicamente estável de 1-(4-carbazolilóxi)-3-[2-(2- } \\
\text { metoxifenóxi)etilamino]2-propanol e processo de preparação. }\end{array}$ & 9.2 (RPI 1995 de 31/03/2009) \\
\hline PI9810920-0 & Novartis AG & $\begin{array}{l}\text { Modificação da forma de cristal de um derivado de n-fenil-2-pirimidinoamina e } \\
\text { processo de preparação }\end{array}$ & 7.1 (RPI 1988 de 10/02/2009) \\
\hline PI9816198-9 & Novartis AG & Forma cristalina de sal de adição de ácido monometanossulfônico & 7.1 (RPI 1988 de 10/02/2009) \\
\hline P19810956-1 & Novartis $A G$ & Macrolidas cristalinas e processo para sua preparação & 9.2 (RPI 1995 de 31/03/2009) \\
\hline PI9811061-6 & Astrazeneca $A B$ & $\begin{array}{l}\text { 11-(4-[2-(2-hidroxietoxi) etila] -1- piperazinila) - dibenzo[b,f] [1,4] tiazepina } \\
\text { cristalina, processos para a preparação e composição farmacêutica }\end{array}$ & 9.2 (RPI 1930 de $02 / 01 / 2008)$ \\
\hline P19812866-3 & Schering Corporation & Polimorfo antifúngico cristalino & 9.2 (RPI 1995 de 31/03/2009) \\
\hline P19813213-0 & Orion Corporation & Forma polimórfica do Levosimendan & 7.1 (RPI 1946 de $02 / 04 / 2008$ ) \\
\hline PI9814476-6 & Sigma-Tau\& Medosan & $\begin{array}{l}\text { Nova forma cristalina de guaiacil éster de ácido 1-metil 5-p-toluilpirrol 2- } \\
\text { acetamidoacético. }\end{array}$ & 7.1 (RPI 1986 de 27/01/2009) \\
\hline PI9814496-0 & Bayer Yakuhin & Forma termodinamicamente estável de Ramatroban. & 7.1 (RPI 1962 de 12/08/2008) \\
\hline P19816067-2 & Astrazeneca $A B$ & Forma A de Omeprazol, omeprazol, processo de preparação. & 7.1 (RPI 1939 de 04/03/2008) \\
\hline P19816198-9 & Novartis AG & Forma cristalina de sal de adição de ácido monometanossulfônico & 7.1 (RPI 1988 de 10/02/2009) \\
\hline PI9911219-1 & Sanofi-Synthelabo & $\begin{array}{l}\text { Forma polimórfica de hidrogenossulfato de clopidogrel, processo de } \\
\text { preparaçăo e composiçãa farmacêutica. }\end{array}$ & 7.1 (RPI 1991 de 03/03/2009) \\
\hline PI9911523-9 & $\begin{array}{l}\text { Bristol-Myers Squibb } \\
\text { Pharma }\end{array}$ & Novas formas cristalinas de Efavirenz e composição farmacêutica. & 7.1 (RPI 1987 de 03/02/2009) \\
\hline PI9912842-0 & $\begin{array}{l}\text { Menarini International } \\
\text { Op. Lux. S.A. }\end{array}$ & Processo para a preparação de forma cristalina do sal de cálcio de Zofenopril & 7.1 (RPI 1995 de 1/03/2009) \\
\hline PI9912622-2 & $\begin{array}{c}\text { Basf } \\
\text { Aktiengesellschaft }\end{array}$ & Ácido R- ou S-lipóico cristalino enanciomericamente puro. & 7.1 (RPI 1995 de 31/03/2009) \\
\hline PI9915669-5 & Bayer Aktiengesellsch & $\begin{array}{l}\text { Modificaçăo cristalina a do ácido 8-ciano-1-ciclopropil-7-(15,6s-2,8- } \\
\text { diazabiciclo-[4.3.0]nonan-8-il)-6-flúor-1,4-diidro-4-oxo-3-qui-nolinocarboxílico }\end{array}$ & 7.1 (RPI 1987 de 03/02/2009) \\
\hline PI9915682-2 & Bayer Aktiengesellsch & $\begin{array}{l}\text { Modificação cristalina b de ácido 8-cian-1-ciclopropil-7-(15, 6s-2,8- } \\
\text { diazabiciclo-[4.3.0]nonan-8-8il)-6-flúor-1,4-dihidro-4-oxo-3-quinolincarboxílico }\end{array}$ & 7.1 (RPI 1987 de 03/02/2009) \\
\hline
\end{tabular}




\section{Resultados e Discussão}

Dos pedidos analisados pela Diquim II entre o período de janeiro de 2008 a março de 2009 relativos às formas polimórficas, observa-se no Gráfico que o maior número de pedidos analisados foi depositado no ano de 1998.

Gráfico 1: Distribuição do número de pedidos de patente analisados pelo INPI entre janeiro de 2008 e março de 2009 relativo a formas polimórficas na área farmacêutica

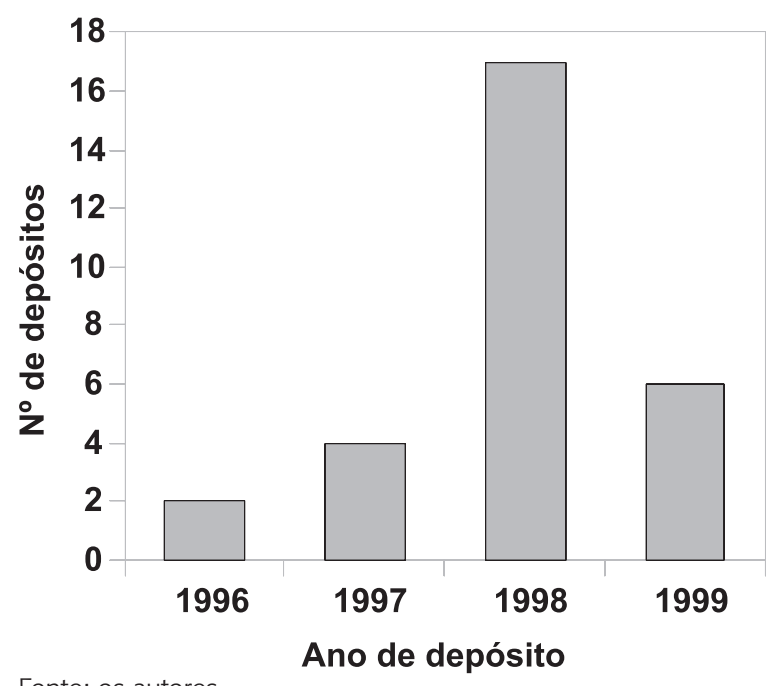

Fonte: os autores.

Da análise do Quadro 1 é possível depreender que o depósito de pedidos de patente de polimorfos iniciouse nos anos 1990 e que, dos 29 pedidos analisados, 15 foram indeferidos, 14 tiveram ciência de parecer, nenhum foi indeferido e não houve depósito por empresa nacional referente a esta matéria.

Através da leitura dos pareceres técnicos dos pedidos de patente que compõem o Quadro 1 foi verificado que na grande maioria não foi possível aferir a novidade da forma polimórfica reivindicada, conforme o disposto no Art. $8^{\circ} \mathrm{e}$ $11^{\circ}$ da LPI, uma vez que a mesma não estava devidamente caracterizada segundo as técnicas de análise mencionadas na proposta de diretrizes de exame do INPI relativa a esta matéria. Ressalta-se que a maior parte dos pedidos de patente listados no Quadro 1, ou seja, 95\%, reivindicam o produto (polimorfo), processo de preparação, composição farmacêutica e uso do polimorfo.

Para cerca de 90\% dos pedidos de patente que reivindicam uma forma polimórfica, o estado da técnica mais próximo é o pedido de patente do composto químico, em geral em uma "Fórmula Markush", onde o estado sólido não foi caracterizado. Nestes casos, para a aferição da novidade da forma polimórfica reivindicada é imprescindível que o depositante caracterize o estado cristalino do composto revelado no estado da técnica e o compare com a forma ora pleiteada no pedido de patente, através da difração de raios- $X$ pelo método do pó e mais outras técnicas complementares, além da comprovação da pureza da amostra. A questão da exigência da comprovação da pureza da forma polimórfica reside no fato de que impurezas na amostra podem comprometer o resultado da análise, bem como dirimir qualquer dúvida de que não há mistura de formas polimórficas. Vale ressaltar que em nenhum dos pedidos já analisados pelo INPI, foram apresentados dados comparativos de difração de raios- $X$ de monocristal, técnica esta suficiente para averiguar a novidade da forma polimórfica pleiteada. Assim, para as formas polimórficas na qual não foi possível aferir a novidade, haveria ainda a possibilidade de proteção do processo de obtenção da mesma.

Observou-se na grande maioria dos pareceres que foi questionada a obviedade da forma polimórfica reivindicada, visto que a maior parte dos pedidos de patente não apresenta nenhum efeito técnico diferenciado, não previsível em relação às formas já descritas no estado da técnica. Não houve nenhum pedido de patente no qual a forma polimórfica apresentasse maior biodisponibilidade do que a já revelada no estado da técnica e grande parte das soluções técnicas residiram na área da tecnologia farmacêutica, ou seja, maior estabilidade química ou física, melhor processabilidade e escoabilidade, entre outras.

Quanto ao processo de obtenção das formas polimórficas, na maioria dos pareceres técnicos foi apontado que os parâmetros considerados essenciais em um processo de cristalização não estavam descritos de forma a permitir a sua reprodução por um técnico no assunto (Art. 24 da LPI). Por exemplo, não estavam descritos no pedido a taxa de resfriamento usada no processo de cristalização, as concentrações das soluções de cristalização, a temperatura utilizada e nem mesmo como foi obtida a semente do cristal que foi utilizado no processo de semeadura. Desta forma, segundo a proposta de diretrizes de exame relativas a formas polimórficas do INPI, tais processos de obtenção de um polimorfo conforme descritos não atendem ao Art. 24 da LPI e, portanto, não são patenteáveis.

Além do questionamento da falta de suficiência descritiva dos processos de obtenção de uma forma polimórfica dos pedidos de patente do Quadro, os examinadores do INPI alegaram que os mesmos decorrem de maneira óbvia e evidente para um técnico no assunto que detém conhecimentos de síntese orgânica, de purificação e cristalização de um composto químico e, assim, os mesmos 
não atendem ao requisito de atividade inventiva segundo o Art. $8^{\circ}$ e 13 da LPI.

Salienta-se que $96,7 \%$ dos pedidos analisados ainda estão em fase de primeira instância, ou seja, ciência de parecer e indeferimento e, portanto, nenhuma decisão final na fase administrativa ainda foi tomada.

No que diz respeito às composições farmacêuticas contendo uma forma polimórfica, em todos os pedidos de patente do Quadro 1 não foram apresentados dados comparativos que justifiquem um efeito diferenciador entre uma composição contendo uma forma polimórfica e aquela já descrita no estado da técnica; desta forma, para as composições farmacêuticas pleiteadas foi alegado que as mesmas não apresentam atividade inventiva e, portanto, não são patenteáveis.

\section{Conclusão}

Hoje, no Brasil, o patenteamento de formas polimórficas na área farmacêutica está inserido no âmbito interministerial e na sociedade civil e é um tema bastante polêmico, principalmente no que diz respeito ao acesso a medicamentos. Neste cenário, o INPI abriu um ciclo de discussões técnicas acerca deste tema e, após a sua análise, tornou pública sua proposta de diretrizes de exame de pedidos de patentes de formas polimórficas.

Como apresentado no texto, os pedidos de patente relativos a formas polimórficas farmacêuticas analisados pelo INPI no período de janeiro de 2008 a março de 2009 não são passíveis de proteção patentária, uma vez que não preenchem alguns dos requisitos de patenteabilidade, além da condição de suficiência descritiva, quando examinadas sob a luz da LPI e da sua proposta de diretrizes de exame.

A contribuição deste artigo é mostrar a importância da proposta de diretrizes de exame de pedidos de patentes de formas polimórficas do INPI, com o intuito harmonizar os exames quanto ao atendimento dos critérios de patenteabilidade e orientar os depositantes de patentes na redação das mesmas.

\section{Referências bibliográficas}

ASSOCIAÇÃO BRASILEIRA INTERDISCIPLINAR DE AIDS. Discussão sobre patentes de polimorfos e segundo uso terapêutico polariza a posição de Ministérios e parlamentares de um lado e do INPI do outro. Disponível em: <http://www.abiaids.org.br>. Acesso em: 20 jan. 2009.
BERMUDEZ, J.A.Z. et al. O acordo trips da OMC e a proteção patentária no Brasil: mudanças recentes e implicações para a produção local e o acesso da população aos medicamentos. Rio de Janeiro: Editora FIOCRUZ/ENSP, 2000.

BOTTOM, R. The role of modulated temperature differential scanning calorimetry in the characterisation of a drug molecule exhibiting polymorphic and glass forming tendencies. International Journal of Pharmaceutics, v.192, n.1, p.4753, 1999.

BRASIL. Lei n 9279, de 14 de maio de 1996. Regula direitos e obrigações relativos à propriedade industrial.

BRASIL. Lei n 5772, 21 de dezembro de 1971, Institui o novo código da propriedade industrial e dá outras providências.

BRASIL. Projeto de Lei n 3.995, de 2008. Diário da Câmara dos Deputados, Brasília, 23 set. 2008. Disponível em: $<$ http://imagem.camara.gov.br/diarios.asp>. Acesso em: 20 jan. 2009.

BRITTAIN, H.G. Polymorpism and solvatomorphism. Journal of Pharmaceutical Science, v.96, n.4, p.705-728. 2006.

CÂMARA DOS DEPUTADOS. INPI: patente de polimorfos favorece inovação tecnológica. Disponível em: <www.camara. gov.br>. Acesso em: 20 jan. 2009.

DE OLHO nas patentes: a inconstitucionalidade das patentes pipelines. Disponível em: <www.deolhonaspatentes.org.br>. Acesso em: 20 jan. 2009.

FROEHLIC, P.E.; GASPARATTO, F.S. Mebendazol: identificação das formas polimórficas em diferentes matérias-primas e medicamentos (referência e genéricos) disponíveis no mercado nacional. Revista de Ciências Farmacêuticas Básica e Aplicada, v.26, n.3, p.205-210, 2005.

GIRO, D. et al. Solid-state characterizations of pharmaceutical hydrates. Journal of Thermal Analysis and Calorimetry, v.68, p.453-465, 2002.

INSTITUTO BRASILEIRO DE DEFESA DO CONSUMIDOR. Patentes de medicamentos: decisão do grupo interministerial prioriza saúde pública. Disponível em: <www.idec.org.br>. Acesso em: 20 jan. 2009.

INPI. Proposta de diretrizes para exame de pedidos de patentes de novas formas polimórficas: metodologia usada e os dados coletados sobre patentes de formas polimórficas em outros países. Disponível em: <www.inpi.gov.br>. Acesso em: 20 jan. 2009. 
INPI. Diretrizes para o exame de pedidos de patente nas áreas de biotecnologia e farmacêutica depositados após 31/12/1994. Revista da Propriedade Intelectual, 2002. Disponível em: <http://www.inpi.gov.br>. Acesso em: 20 jan. 2009.

INPI. Proposta de diretrizes para o exame de pedidos de patentes de novas formas polimórficas. Disponível em: <http://www.inpi.gov.br>. Acesso em: 20 jan. 2009.

INPI. Reunião do Grupo de Estudos sobre Polimorfismo, 1., 2007. Disponível em: <www.inpi.gov.br>. Acesso em: 20 jan. 2009.

INPI. Reunião do Grupo de Estudos sobre Polimorfismo, 2., 2007. Disponível em: <www.inpi.gov.br>. Acesso em: 20 jan. 2009.

INPI. Reunião do Grupo de Estudos sobre Polimorfismo, 3., 2007. Disponível em: <www.inpi.gov.br>. Acesso em: 20 jan. 2009.

JANNUZZI, A.H.L.; VASCONCELLOS, A.G.; SOUZA, C.G. Especialidades do patenteamento no setor farmacêutico: modalidade e aspectos de proteção intelectual. Cadernos de Saúde Pública, v.24, n.6, p.1205-1218, 2008.

LIMA, D.M.M. As estratégias de extensão da proteção e/ ou bloqueio da concorrência da indústria farmacêutica: o caso das patentes de polimorfo. 2007. (MBA em Políticas Públicas - Enfase em Inovação e Propriedade Intelectual) Centro de Ciências Jurídicas e Econômicas, UFRJ/INPI, Rio de Janeiro, 2007.

LONGA, L.C.D. O gerenciamento da informação tecnológica contida na literatura patentária: uma proposta para a FIOCRUZ. Dissertação (Mestrado) - Escola Nacional de Saúde Pública Sérgio Arouca, Fundação Oswaldo Cruz, Rio de Janeiro, 2007.

PRÓ-GENÉRICOS. Barreiras relacionadas à patente para entrada de medicamentos genéricos no mercado da União Européia. Disponível em: <www.progenericos.org.br>. Acesso em: 17 jan. 2009.

TACHINARDI, M.H. A guerra das patentes: o conflito Brasil $x$ EUA sobre propriedade intelectual. Rio de Janeiro: Editora Pa e Terra, 1993. 